\title{
Occurrence Delays of Metastatic Relapses of Breast Cancers Treated at University Hospital of Treichville (Abidjan-Cote d'Ivoire)
}

\section{Lydie Estelle Djanhan 1 , Jean Marc Dia ${ }^{2 *}$, Boston Mian³, Mouhideen Oyelade², Aboulaye Diallo², Privat Guié2, Simplice Anongba ${ }^{2}$}

${ }^{1}$ Department of Gynecology and Obstetrics, University Hospital of Bouaké, Bouake, Côte d'Ivoire ${ }^{2}$ Department of Gynecology and Obstetrics, University Hospital of Treichville, Abidjan, Côte d'Ivoire ${ }^{3}$ Department of Gynecology and Obstetrics, University Hospital of Cocody, Abidjan, Côte d'Ivoire Email: ${ }^{* j m l a m i n e d i a @ y a h o o . f r ~}$

How to cite this paper: Djanhan, L.E., Dia, J.M., Mian, B., Oyelade, M., Diallo, A., Guié, P. and Anongba, S. (2017) Occurrence Delays of Metastatic Relapses of Breast Cancers Treated at University Hospital of Treichville (Abidjan-Cote d'Ivoire). Journal of Cancer Therapy, 8, 924-932. https://doi.org/10.4236/jct.2017.811081

Received: October 4, 2017

Accepted: November 10, 2017

Published: November 13, 2017

Copyright (c) 2017 by authors and Scientific Research Publishing Inc. This work is licensed under the Creative Commons Attribution International License (CC BY 4.0).

http://creativecommons.org/licenses/by/4.0/

\section{(c) (i) Open Access}

\begin{abstract}
Objective: Describe the occurrence delays of metastatic relapses of breast cancer based on the characteristics of the original tumor. Methodology: This is a retrospective and cohort study conducted from January 2000 to December 2015 on patients with metastatic relapse of breast cancer. Results: Out of 178 patients collected, the metastatic relapses were estimated at $49 \%$, occurring in patients with an average age of 53.4 years. The majority of the patients was educated (91.6\%) and did not have a high socioeconomic level (88.2\%). The initial tumors were mainly at a clinical stage III (47.8\%), SBR grade III (47.2\%), high index Ki 67 (46.5\%), negative RH (79.3\%) and HER2 negative (58\%). Metastases were unique in general $(62.9 \%)$, dominated by bone locations (36.6\%), with an average age of occurrence of 2.4 years. After the occurrence of these metastases, the cumulative survival rate was $5 \%$ at 3 years, and zero to 5 years. Conclusion: Metastatic relapses were common with poor prognosis.
\end{abstract}

\section{Keywords}

Breast Cancer, Risk Factors, Metastatic Relapses

\section{Introduction}

Breast cancer is the first cancer of woman in Cote d'Ivoire as in many countries of the world [1] [2], and its prognosis is closely related to the occurrence of metastases. Also after the curative treatment of non-metastatic forms, monitoring should be careful to quickly take care of locoregional and metastatic relapses that may occur. ASCO (American Society of Clinical Oncology) recommends clinical 
monitoring based on examination and clinical examination, every 4 months for 3 years, then every 6 months for the next 2 years, and once a year for the rest of

life [3]. For additional examinations, only mammography and breast ultrasound should be performed annually, and other tests (chest x-ray, tumor markers, abdomino-pelvic ultrasound, bone scintigraphy, etc.) will be proposed only before functional signs [4].

In developing countries where there is no breast cancer screening program, the management of non-metastatic tumors is late, and exposes patients to high risk of metastatic relapse after initial treatment. Yet there are few publications on metastatic relapses in African literature.

This study was conducted with the objective to describe occurrence delays of metastatic relapses observed in our department.

\section{Methodology}

This is a retrospective and cohort study conducted from January 2000 to December 2015 (16 years) in the gynecology department of the University Hospital of Treichville (CHUT).

It involved patients who benefited from a radical surgery with curative intent for nonmetastatic invasive breast cancer in our department between January 2000 and December 2010 and followed until December 2015.

These patients with non-metastatic invasive breast cancer have all initially benefited from a locoregional treatment and a systemic treatment. Locoregional treatment consisted in a total mastectomy, according to Patey, with axilary dissection by lack of radiotherapy and sentinel lymph nodes sampling. Regarding the systemic treatment, an adjuvant chemotherapy (FAC or FEC protocol) was performed in all patients, and only patients at Clinicalstage II and III received a neoadjuvant chemotherapy (same protocol) before surgery. At the end of the treatment and outside of any new event, the patients are followed according to ASCO recommendations.

We included in the study all patients who showed a metastatic breast cancer relapse during follow-up after initial treatment.

Patients operated outside our services, and those with breast cancer initially metastatic at initial diagnosis, were not included in the study.

Our data were collected on a survey patient records, chemotherapy registers, and anatomopathological findings.

The sample included 178 patients from whom the information was collected on a standard survey form. The analysis were done by the software Word, Excel, epi info and the statistical tests used were the calculations of the averages and frequencies.

\section{Results}

\subsection{Epidemiological Characteristics}

- Frequency of metastases 
Between 2000 and 2010, 363 patients underwent radical breast cancer surgery and during surveillance until 2015, we found that 178 patients (49\%) developed metastasis and we lost sight of 185 patients (51\%) before the occurrence of metastases. The average follow-up duration was 3 years 7 months (extreme 9 months7 years 3 months) and cumulative survival without metastasis was $60 \%$ at 3 years and $43 \%$ at 5 years.

- Sociodemographic characteristics of patients

Patients had an average age of 53.4 years (extreme 38 - 74) and 62.4\% were over 50 years of age, $91.6 \%$ were educated, and $88.2 \%$ did not have a high socioeconomic level.

\subsection{Characteristics of Metastases}

- Location of metastases

Metastases were unique in 112 patients (62.9\%), dominated by osseous metastases (41 patients), lung (28 patients), liver (19 patients), hollow abdominal viscera ( 9 patients) and peritoneal ( 3 patients).

- Occurrencechronology of metastases

The average occurrence delay of metastases was 2.4 years (extreme 8 months 7 years 6 months). And they occurred in less than 24 months in 84 patients (47.2\%) and over 24 months in 94 patients (52.8\%). At 5 years $95.4 \%$ of patients had metastases.

3-Relation between the prognostic factors of the initial tumor and the occurrence delay of metastases.

\section{Discussion}

\subsection{Epidemiological Characteristics}

- Frequency of metastases

Metastatic relapses were frequent in our study population, estimated at $49 \%$ with a cumulative survival rate without metastasis at 3 years of $60 \%$ (Figure 1). And this frequency seems underestimated given the high rate of loss of sight (51\%) that we found. In African literature we have not found any articles estimating the frequency of metastatic relapses. On the other hand, in developed countries where the breast cancer management is performed earlier, and with a better technical equipment than in our countries, metastatic relapses are generally less frequent, estimated at less than $20 \%$ in ten years [5] [6] [7]. But it is important to question these figures, as even in these developed countries, in the late-patient population, there are high rates of metastatic relapse after mastectomy : greater than $50 \%$ in 10 years [8]

- Age

Our patients had an average age of 53.4 years and the majority $(62.4 \%)$ was over 50 years of age (Table 1 ). In the literature, it is indeed reported that metastatic relapses are more frequent in women over 50 years of age, and locoregional relapses more frequent in younger women [9] [10]. Menopausal status could af- 
fect the occurrence of these metastases, but the retrospective aspect of our study does not allow us to explore this parameter.

- Education level

The majority of our patients was educated (91.6\%) (Table 1) and overall they had a sufficient level of education (secondary and higher) to better understand the interest of breast cancer screening. This screening would have permitted the management of the primary lesion at earlier stages, in order to limit the risk of metastatic relapses. But the absence of screening programs remains a reality in our regions, so that the notion of screening remains unknown to the population.

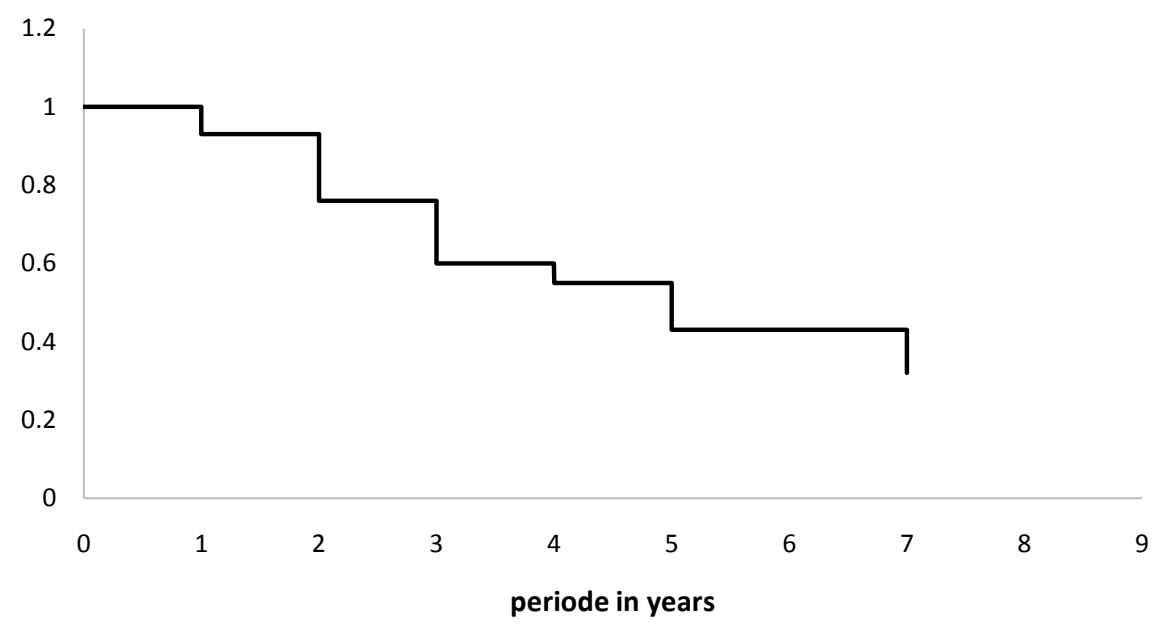

Figure 1. Survival curve without metastatic relapses of patients who underwent radical surgery for invasive breast cancer from 2000 to 2010 .

Table 1. Distribution of patients according to their socio-demographic characteristics.

\begin{tabular}{ccc}
\hline Socio-demographic characteristics & Numbers & Frequency (\%) \\
\hline Age (years) & 8 & 4.5 \\
$-\quad<40$ years & 59 & 33.1 \\
$-\quad 40-50$ & 63 & 35.4 \\
$-\quad 50-60$ & 48 & 27 \\
$-\quad>60$ & 178 & 100 \\
$\quad$ Total & & \\
Level of education & 15 & 8.4 \\
$-\quad$ Not educated & 31 & 17.4 \\
$-\quad$ Primary & 61 & 34.3 \\
$-\quad$ Secondary & 71 & 39.9 \\
$-\quad$ Superior & 178 & 100 \\
$-\quad$ Total & & \\
Socio-economic level & 13 & 7.3 \\
$-\quad$ Low & 144 & 80.9 \\
$-\quad$ medium & 21 & 11.8 \\
$-\quad$ High & 178 & 100 \\
\hline
\end{tabular}


In a study conducted in our country on women having reached a secondary school level, Guié found that only $21 \%$ of women over 50 had already practiced breast cancer screening and in $42.1 \%$ of cases this screening went back to more than 4 years [11].

- Socio-economic level

The patients in the study did not generally have a high socio-economic level (88.2\%) (Table 1), constituting a real obstacle for the management of their disease (both the primary tumor and the metastases). In our country the management of cancers is expensive, and remains the responsibility of the patients because there is no social policy of health insurance. And in a study conducted in our country, Touré found that the lack of financial means caused the diagnostic delay of breast cancer in $36 \%$ of cases [1].

\subsection{Characteristics of Metastases}

\section{- Location}

We found that the majority of the metastases of our patients was unique (62.9\%), and affected mainly bones, lung, liver, and brain. Several authors have also highlighted the high incidence of bone and lung forms [12] [13]. As for Anhoux [14] he found, in his study conducted in our country, that the most common forms were pulmonary and hepatic. But we agree with the African authors who believe it is premature to conclude preferential locations in our conditions due to an underestimation related to insufficiency of paraclinical exploration: MRI and PET scan (Positron Emission Tomography) [14] [15].

- Occurrence delay of metastatic relapses

After the initial treatment of our patients, metastases occurred within an average delay of 2.4 years. At 24 months, almost half of the patients (47.2\%) had metastases and at 5 years almost all patients (95.4\%) had metastases. It is recognized that the majority of metastases occur within the first 5 years justifying an increased surveillance during this period [3] [5] [16]. But cases of late metastases occurring beyond 20 years have been reported, imposing also a long-term monitoring of all patients for breast cancer [3] [17] [18].

\subsection{Relationship between the Prognostic Factors of the Initial Tumor and the Occurrence Delay of Metastases}

1) Occurrence delay-Histological type of initial tumor

In our study $41.8 \%$ of patients having an invasive ductal carcinoma and $58.9 \%$ of patients who have had invasive lobular carcinoma, relapsed in less than 24 months (Table 2). In the literature, it is assumed that the histological type has no influence on prognosis : All invasive cancers have the same prognosis [19] [20].

2) Occurrence delay-initial stage of tumor

In the study, the majority of patients who relapsed within 24 had an advanced stage: II and III (Table 2). In the study of Anvo [21] in which it has identified all patients with metastasis, $52.5 \%$ of the population had an initial tumor at stage III. Carter and Host [22] [23] have highlighted the pejorative role of the advanced 
Table 2. Relation between the prognostic factors of the initial tumor and the occurrence delay of metastases.

\begin{tabular}{|c|c|c|c|}
\hline Characteristics of the primary tumor & $<24$ months & $>24$ months & Total \\
\hline \multicolumn{4}{|l|}{ Histological type } \\
\hline - IDC & $51(41.8 \%)$ & $71(58.2 \%)$ & $122(100 \%)$ \\
\hline - ILC & $33(58.9 \%)$ & $23(41.1 \%)$ & $56(100 \%)$ \\
\hline - Total & 84 & 94 & 178 \\
\hline \multicolumn{4}{|l|}{ Clinical Stage } \\
\hline$-\quad I$ & $7(25 \%)$ & $18(72 \%)$ & $25(100 \%)$ \\
\hline - $\quad$ II & $25(36.7 \%)$ & $43(63.3 \%)$ & $68(100 \%)$ \\
\hline$-\quad$ III & $52(61.1 \%)$ & $33(38.9 \%)$ & $85(100 \%)$ \\
\hline - Total & 84 & 94 & 178 \\
\hline \multicolumn{4}{|l|}{ Grade SBR } \\
\hline$-\quad I$ & $9(2.9 \%)$ & $22(97.1 \%)$ & $31(100 \%)$ \\
\hline$-\quad$ II & $28(44.4 \%)$ & $35(55.6 \%)$ & $63(100 \%)$ \\
\hline$-\quad$ III & $47(55.9 \%)$ & $37(44.1 \%)$ & $84(100 \%)$ \\
\hline - Total & 84 & 94 & 178 \\
\hline \multicolumn{4}{|l|}{ Ki 67} \\
\hline - Low & $6(75 \%)$ & $2(25 \%)$ & $8(100 \%)$ \\
\hline - Moderate & $13(56.5 \%)$ & $10(43.5 \%)$ & $23(100 \%)$ \\
\hline - High & $17(62.9 \%)$ & $10(37.1 \%)$ & $27(100 \%)$ \\
\hline - Total & 36 & 22 & 58 \\
\hline \multicolumn{4}{|l|}{ HR } \\
\hline - Positive & $3(25 \%)$ & $9(75 \%)$ & $12(100 \%)$ \\
\hline - Negative & $38(82.6 \%)$ & $8(17.4 \%)$ & $46(100 \%)$ \\
\hline - Total & 41 & 17 & 58 \\
\hline \multicolumn{4}{|l|}{ HER2 } \\
\hline - Positive & $8(38.1 \%)$ & $13(61.9 \%)$ & $21(100 \%)$ \\
\hline - Negative & $30(81.1 \%)$ & $7(18.9 \%)$ & $37(100 \%)$ \\
\hline - Total & 38 & 20 & 58 \\
\hline
\end{tabular}

IDC: Infiltrating Ducta Carcinoma. ILC: Infiltrating Lobular Carcinoma. HR: Hormone Receptors. SBR: Scarff Bloom Richardson.

initial stage of the disease on the occurrence of relapses.

3) Occurrence delay-histological prognostic factors

Just as the initial stage of the disease, the usual histological prognostic factors govern the risk of metastatic relapse especially in the first 5 years following the initial curative treatment. [24] Thus the more the histological and prognostic grade SBR is high, the more relapses are frequent and precocious with a high mortality [25] [26]. In our series, we effectively found that metastatic relapses were more common in patients who had a higher grade (Table 2).

Concerning the other prognostic factors whose diagnosis is performed by immunohistochemistry (Receptor hormonal, Ki67, HER2), they were explored in only 58 patients (32.6\%) because the laboratories were not equipped to conduct this examination during the period of study. These examinations were car- 
ried out abroad (France) at costs beyond the reach of the majority of patients. However the majority of patients who made these examinations had tumors with negative hormone receptors, an index Ki 67 high, and over expressed HER2.

The role of these various factors on the prognosis is also well known. The tumors that do not express estrogen receptors (ER-) relapse more frequently in the first 5 years, and tumors having a high index Ki 67 have a worse prognosis compared to tumors with moderate or low index [27] [28]. Moreover the HER2 overexpression is a poor prognostic factor especially for $\mathrm{N}+$ patients, and high grade SBR [29] [30].

\section{Conclusion}

Our study has shown us that the management of breast cancer poses enormous problems. Metastases occurred early after the initial treatment. For the improvement of the survival of patients with breast cancer, we must popularize screening sessions and early diagnosis in developing countries.

\section{References}

[1] Toure, M., Nguessan, E., Bambara, A.T., Kouassi, Y.K.K., Dia, J.M.L. and Adoubi, I. (2013) Factorslinked to Late Diagnosis in Breast Cancer in Sub-Saharan Africa: Case of Côte d'Ivoire. Gynécologie Obstétrique et Fertilité, 41, 696-700. https://doi.org/10.1016/j.gyobfe.2013.08.019

[2] Ferlay, J., Soerjomataram, I., Ervik, M., Dikshit, R., Eser, S., Mathers, C., Rebelo, M., Parkin, D.M., Forman, D. and Bray, F. (2013) GLOBOCAN 2012 v1.0, Cancer Incidence and Mortality Worldwide: IARC Cancer Base No. 11. Lyon, France: International Agency for Research on Cancer. http://globocan.iarc.fr

[3] American Society of Clinical Oncology (1999) Update of Recommended Breast Cancer Surveillance Guidelines. Journal of Clinical Oncology, 17, 1080-1082.

[4] Sebban, E. (2006) Pour la surveillance intensive après traitement du cancer du sein. Gynécologie Obstétrique et Fertilité, 34, 268-270.

[5] Kamby, C. (1990) The Pattern of Metastases in Human Breast Cancer: Methodological Aspects and Influence of Prognostic Factors. Cancer Treatment Reviews, 17, 37-61. https://doi.org/10.1016/0305-7372(90)90075-Q

[6] Aukema, T.S., Russell, N.S., Wesseling, J. and Rutgers, E.J. (2009) Extensive Soft Tissue Resection with Autologous Tissue Closure for Locally Recurrent Breast Cancer: Lasting Local Control and Acceptable Morbidity. European Journal of Surgical Oncology (EJSO), 35, 469-474. https://doi.org/10.1016/j.ejso.2008.12.015

[7] Berenice, Q. (2014) Cancer du sein localement avancé : facteurs prédictifs de mastectomie après chimiothérapie néoadjuvante. A propos d'une série rétrospective de 247 patientes traitées à l'Institut Bergonié. Médecine humaine et pathologie, 1-85.

[8] Early Breast Cancer Trialist'Collaborative Group. Effects of Radiotherapy and of Differences in the Extent of Surgery for Early Breast Cancer on Local Recurrence and 15 Year Survival: An Overview on the Randomized Trials. Lancet, 366, $2087-$ 2106.

[9] Chevallier, B., Heintzman, F. and Mosseri, V. (1989) Quels sont les facteurs pronostics du cancer du sein opérable sans envahissement ganglionnaire axillaire histologique? Résultats d'une analyse uni et multifactorielle. Bulletin du Cancer, 76, 51-60. 
[10] De La Rochefordière, A., Asslain, B. and Campana, F. (1993) Age Prognostic Factor in Premenopausal Breast Carcinoma. Lancet, 341, 1039-1043. https://doi.org/10.1016/0140-6736(93)92407-K

[11] Guié, P., Dia, J.M., Saki, C., Bohoussou, E., Nguessan, E., Yao, I., et al. (2013) Dépistage des cancers du col de l'utérus et du sein: Connaissances et attitudes des femmes fonctionnaires vues en consultation au CHUT. International Medical Malpractice, 15, 141-145.

[12] Ferrero, J.M., Pivot, X. and Namer, M. (1995) Association Mitoxantrone-Vinorelbine en première ligne thérapeutique dans le cancer du sein métastatique. Bulletin $d u$ Cancer, 82, 2002-2007.

[13] Renaud, R., Gairard, B. and Bellocq, J.P. (1991) Le risque de métastases à distance In Cancer du sein: Surveillance après traitement. BREMOND A. Medition, 16-26.

[14] Anhoux, A., Adoubi, I. and Echimane, K.A. (2002) Sites métastatiques du cancer du sein de la femme noire en Côte d'Ivoire. Espérance Médicale, 9, 622-625.

[15] Harouna, D.Y., Boukary, I. and Kanou, H.M. (2002) Le cancer du sein de la femme au Niger. Médecine d Afrique noire électronique, 1, 39-43.

[16] Lansac, J. and Diouf, A. (1998) La surveillance d'une femme traitée pour cancer du sein. Journal de Gynécologie Obstétrique et Biologie de la Reproduction, 27, 21-23.

[17] Mamby, C.C., Love, R.R. and Heaney, E. (1993) Metastatic Breast Cancer 39 Years after Primary Treatment. Wisconsin Medical Journal, 92, 567-569.

[18] Tueche, S.G., Nguyen, H., Larsimont, D. and Andry, G. (1999) Lateonset of Tonsillar Metastasis from Breast Cancer. European Journal of Surgical Oncology, 25, 439-448. https://doi.org/10.1053/ejso.1999.0672

[19] Belghiti, L., Chenguiti-Ansari, A. and Elaanine, M. (2002) Facteur pronostic dans le cancer du sein. Espérance Médicale, 9.

[20] Zavetsky, J. and Gardner, B. (1996) Post Excisinal Recurrence of Carcinoma of the Breast. Journal of the American College of Surgeons, 182, 71-77.

[21] Anvo, G. (2003) Rechutes métastatiques des cancers du sein traités à Abidjan: À propos de 80 cas colligés. ThèseMéd, Abidjan, 1-205.

[22] Carter, C.L., Allen, C. and Henson, D. (1989) Relation of Tumor Size Lymphe Node Status, and Survival in 24740 Breast Cancer Cases. Cancer, 63, 181-187. https://doi.org/10.1002/1097-0142(19890101)63:1<181::AID-CNCR2820630129>3.0 .CO;2-H

[23] Host, H. and Brennhovd, I. (1975) Combined Surgery and Radiation Therapy versus Surgery Alone in Primary Mammary Carcinoma. Acta Radiologica, 14, 25-32.

[24] Spielmann, M., Riofrio, M. and Zelek, L. (2000) Facteurs pronostiques du cancer du sein et facteurs prédictifs de la réponse au traitement. La Lettre du Cancérologue, 9 , 29-35

[25] Treilleux, I. and Brémond, A. (2002) Pronostic des cancers du sein. Encycl Méd Chir, 865-F-20, 1-7.

[26] Contesso, G., Mouriesse, H. and Friedman, S. (1987) The Importance of Histologic Grade in Long-Term Prognosis of Breast Cancer: A Study of 1010 Patients, Uniformly Treated at the Institut Gustave-Roussy. Journal of Clinical Oncology, 5, 1378-1386. https://doi.org/10.1200/JCO.1987.5.9.1378

[27] Hortobagyi, G.N., Kau, S.-W. and Buzdar, A.U. (2004) What Is the Prognosis of Patients with Operable Breast Cancer Five Years after Diagnosis? Proceedings of American Society of Clinical Oncology, 22, Abstract 585.

[28] Dowseet, M., Nielsen, T.O., A’Hern, R., Bartlett, J., Coombes, R.C., Cuzick, J., et al. 
(2011) Assessment of Ki 67 in Breast Cancer: Recommendation from the International in Breast Cancer Working Group. Journal of the National Cancer Institute, 103, 1656-1664. https://doi.org/10.1093/jnci/djr393

[29] Nieto, Y., Nawaz, S. and Cagnoni, P.J. (1999) Overexpression of Her 2/Neu (H2N), But Not P53 Mutations Is a Poor Prognostic Factor of High-Risk Primary Breast Cancer (HRPBC) Treated with High-Dose Chemotherapy (HDC) and Autologous Stem-Cell Transplant (ASCT). Proceedings of American Society of Clinical Oncology, 18, Abstract 290.

[30] Wolff, A.C., Hammond, M.E., Hicks, D.G. and Dowseet, M. (2013) Recommendations for Human Epiderma Growth Factor Receptor 2 Testing in Breast Cancer. American Society of Clinical Oncology/College of American Pathologists Clinical Practice Guideline Update. Journal of Clinical Oncology, 31, 3997-4013.

https://doi.org/10.1200/JCO.2013.50.9984 